\title{
- Metabolismo do ferro nos \\ animais domésticos: revisão
}

\section{- Iron metabolism in domestic animals: a review}

\section{- Metabolismo del hierro en los animales domésti- cos: revisión}

* Nayro Xavier de Alencar ${ }^{1}$ - CRMV-SP - $\mathbf{n}^{0} 8213$

Aguemi Kohayagawa ${ }^{2}$ - CRMV-SP - $n^{\circ} 674$

Karla Conceição Higino de Campos $^{3}$ - CRMV-SP - no 13579

1 Doutorando em Medicina Veterinária - FMVZ - UNESP - Botucatu/SP.

Professor Titular do Departamento de Clínica Veterinária - FMVZ - UNESP - Botucatu/SP.

Médica Veterinária Residente do Laboratório Clínico Veterinário - FMVZ - UNESP - Botucatu/SP.

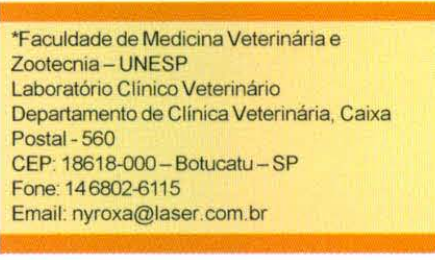

*Faculdade de Medicina Veterinária e

aboratório Clinir

Departamento de Clinica Veterinária Caixa

CEP: $18618-000-$ Botucatu-SP

Email:nyroxa@laser.com.br

\section{RESUMO}

O estudo do metabolismo do ferro tem sido de fundamental importância no entendimento dos processos mórbidos que envolvem este metabolismo, como as anemias ferroprivas ou, ainda, a anemia da doença inflamatória, que é a principal causa de anemia em pequenos animais e provavelmente a mais comumente encontrada em Medicina Veterinária. Embora ainda existam muitas lacunas no entendimento deste metabolismo, avanços recentes têm resultado em melhor compreensão dos efeitos provocados pelos desequilíbrios deste elemento. O propósito deste trabalho foi o de apresentar uma revisão sobre o metabolismo do ferro nas espécies domésticas, enfatizando os exames laboratoriais utilizados para sua avaliação.

Palavras-chave: Metabolismo do ferro. Anemia. Hematologia. Medula óssea.

\section{Introdução}

ferro é um metal de transição e a extensão de sua utilidade biológica está na capacidade de existir em diversos estados de oxidação e de formar muitos complexos diferentes. Em alguns aspectos, o ferro pode ser considerado como um oligoelemento, necessário em quantidades relativamen- te pequenas como cofator de muitas enzimas. Entretanto, sua presença em quantidades muito maiores em uma proteína, a hemoglobina, faz com que as necessidades do organismo sejam mais difíceis de corrigir do que as de outros oligoelementos metálicos, sendo mais comum seu desequilíbrio (WORWOOD, 1996).

O ferro é o segundo metal mais abundante e o quarto elemento mais comum na crosta terrestre. Ape- 
sar desta grande abundância natural, a maioria do ferro presente na natureza existe na forma férrica $(\mathrm{Fe} 3+)$, que é amplamente indisponível para a maioria dos sistemas biológicos. Isto se deve a sua insolubilidade na água, exceto quando em solução ácida. Em $\mathrm{pH} 7,0$ os sais ferrosos $\left(\mathrm{Fe}^{+}\right)$são relativamente solúveis, mas na presença de oxigênio são rapidamente oxidados à forma férrica, quase insolúvel (WORWOOD, 1996; ANDREWS; SMITH, 2000).

O ferro está presente no organismo dos animais, principalmente sob a forma de complexos ligados a proteínas, como os compostos heme (hemoglobina ou mioglobina), enzimas heme (citocromos, catalases e peroxidases) ou compostos não- heme (enzimas flavina-Fe, transferrina e ferritina) (NIMEH; BISHOP, 1980; HAYS; SWENSON, 1996).

A combinação do ferro a diversas proteínas é, sem dúvida, um importante mecanismo de defesa orgânica, visto que o ferro livre é capaz de catalisar a formação de espécies reativas do oxigênio, podendo trazer conseqüências graves para membranas celulares e DNA. Desta forma, o ferro intracelular está ligado ou incorporado a várias proteínas ou quelatos para reduzir sua toxicidade. Estas proteínas ou quelatos são responsáveis pela absorção, estoque e atividade biológica do ferro (SMITH, 1997; ANDREWS; SMITH, 2000).

As funções do ferro nos processos respiratórios ocorrem por meio da sua atividade de oxidação e redução, bem como pela sua capacidade para transportar elétrons. Essa propriedade intensifica-se muito quando o ferro está combinado à proteína (HAYS; SWENSON, 1996).

\section{Distribuição do ferro no organismo}

O conteúdo corporal total de ferro nos ruminantes aproxima-se de $60 \mathrm{ppm}$. O ferro está presente em todas as células do organismo e intervém em muitas reações bioquímicas (MILLER; RAMSEY; MADSEN, 1993).

Existem variações na literatura sobre a quantidade de ferro no organismo (Quadro 1), entretanto, sabe-se que as proporções mais importantes da totalidade do ferro corporal encontram-se na

hemoglobina (60-70\%), na mioglobina (3\%), armazenado sob a forma de ferritina e hemossiderina ( $26 \%$ ) e em várias enzimas (catalases, peroxidases, citocromos) numa pequena proporção $(<1 \%)$ (MILLER; RAMSEY; MADSEN, 1993; HAYS; SWENSON, 1996).

A maior parte do ferro nos animais está localizado no eritrócito, como hemoglobina. A hemoglobina é constituída por um tetrâmero formado por dois pares de cadeias polipeptídicas, as globinas. A cada uma das quatro cadeias, liga-se um grupo prostético (NR-1), o heme, que é um complexo de ferro e protoporfirina (Figura 1). A síntese da hemoglobina processa-se concomitantemente à maturação dos eritrócitos na medula óssea. Cerca de $65 \%$ da hemoglobina é sintetizada na fase eritroblástica e $35 \%$ na fase de reticulócito (MELO, 1984).

A mioglobina, encontrada dentro das células musculares, está relacionada com a hemoglobina do sangue, tanto na estrutura como na função. E um transportador de oxigênio, que serve como reservatório deste elemento para as células musculares e para remoção do dióxido de carbono. Cada molécula de mioglobina contém um átomo de ferro. A concentração da mioglobina varia com a espécie e a atividade muscular (ANDERSON et al., 1990; SMITH, 1997).

A mioglobina está relacionada à espécie e depende da atividade muscular, refletindo-se na sua con- 
centração no tecido muscular (SMITH, 1997). Esta molécula é particularmente abundante nos músculos de mamíferos marinhos como baleias e focas, sendo esta característica que permite estes animais permanecerem por longos períodos submersos na água (SCHMIDH-NIELSEN, 1999).

Após a destruição do eritrócito pelo sistema mononuclear fagocitário (Figura 2) ou na presença de quantidades de ferro suficientes para suprir as necessidades eritropoiéticas, o ferro é armazenado sob a forma de dois complexos ferroprotéicos, a ferritina e a hemossiderina. Os principais locais de armazenamento deste ferro são as células parenquimatosas do fígado e as células reticuloendoteliais da medula óssea, baço e fígado (ANDERSON et al., 1990).

A ferritina consiste de ferro e proteína. A porção protéica, denominada de apoferritina, contém 24 monômeros e, pelo menos, dois tipos de subunidades, denominadas $\mathrm{H} \mathrm{e} \mathrm{L}$, cujas proporções variam com a espécie e o tecido em que se encontram (SMITH, 1997).

A união dos monômeros forma uma espécie de concha com alguns poros por onde o ferro entra na forma ferrosa $\left(\mathrm{Fe}^{2+}\right)$. No interior da molécula, o ferro sofre oxidação para a forma férrica $\left(\mathrm{Fe}^{3+}\right)$, sendo, em seguida, hidrolisado e polimerizado. Se totalmente saturada, a molécula de ferritina pode conter até 4.500 átomos de ferro (WORWOOD, 1996; SMITH, 1997)

A ferritina garante uma reserva solúvel de ferro no interior das células, que poderá ser usada na síntese de proteínas e enzimas que contêm o ferro. Pequenas quantidades de ferritina circulam no plasma, e esta concentração está relacionada à quantidade de depósito de ferro no organismo (WORWOOD, 1990).

Outro complexo ferro-protéico, a hemossiderina, é a forma mais concentrada de reserva de ferro no organismo (ANDERSON et al., 1990). O ferro da hemossiderina apresenta uma considerável semelhança química com o ferro da ferritina (WORWOOD, 1996), porém com uma maior relação ferro:proteína (SMITH, 1997). Sua concentração em relação à ferritina aumenta quando os níveis de reserva são (ANDERSON et al., 1990).

\section{APROVEITAMENTO DO FERRO NO S.M.F.}

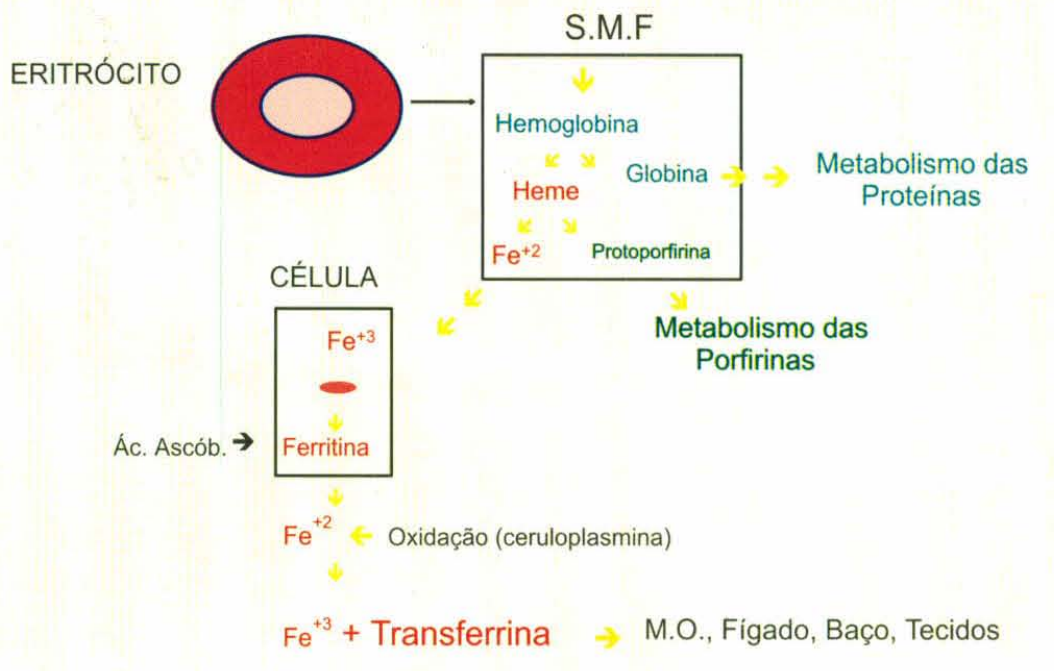

Figura 2 - Esquema de aproveitamento do ferro pelo sistema mononuclear fagocitário.

\section{Ciclo plasmático do ferro}

O ferro é transportado entre alguns compartimentos (plasma e líquidos extravasculares) pela transferrina (Figura 3). Esta proteína transportadora específica de ferro é constituída por uma única cadeia polipeptídica, com massa molecular de $78 \mathrm{KDa}$ (quiloDaltons), que contém 679 aminoácidos (WORWOOD, 1996; SMITH, 1997).

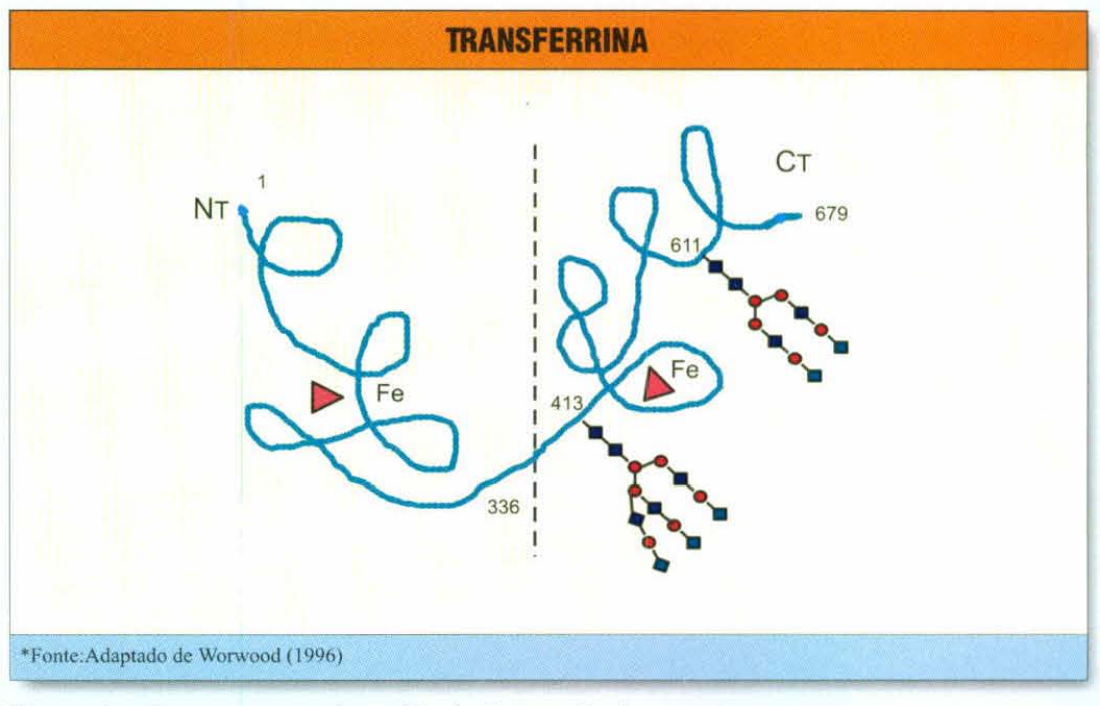

Figura 3 - Representação da molécula de transferrina.

A transferrina é sintetizada no retículo endoplasmático rugoso do hepatócito, nos macrófagos do tecido linfóide, nas glândulas salivares e mamárias e nos ovários e testículos (THORBECKE et al., 1973). 
A molécula de transferrina possui dois domínios com elevado grau de homologia. Os domínios do terminal- $\mathrm{N}$ (resíduo 1-336) e do terminal-C (337679) possuem um sítio de ligação para o ferro e ainda duas cadeias $\mathrm{N}$ oligossacarídeas acopladas no domínio do terminal-C (resíduos 413 e 611). Dessa forma, cada sítio liga um átomo de ferro sob a forma de íon férrico. A ligação do ferro a estes sítios requer uma ligação concomitante de um íon (carbonato ou bicarbonato). $\mathrm{O}$ ferro como íon férrico fica firmemente ligado à transferrina em um $\mathrm{pH}$ neutro, mas é liberado quando o $\mathrm{pH}$ fica abaixo de 5,5 (WORWOOD, 1996; SMITH, 1997).

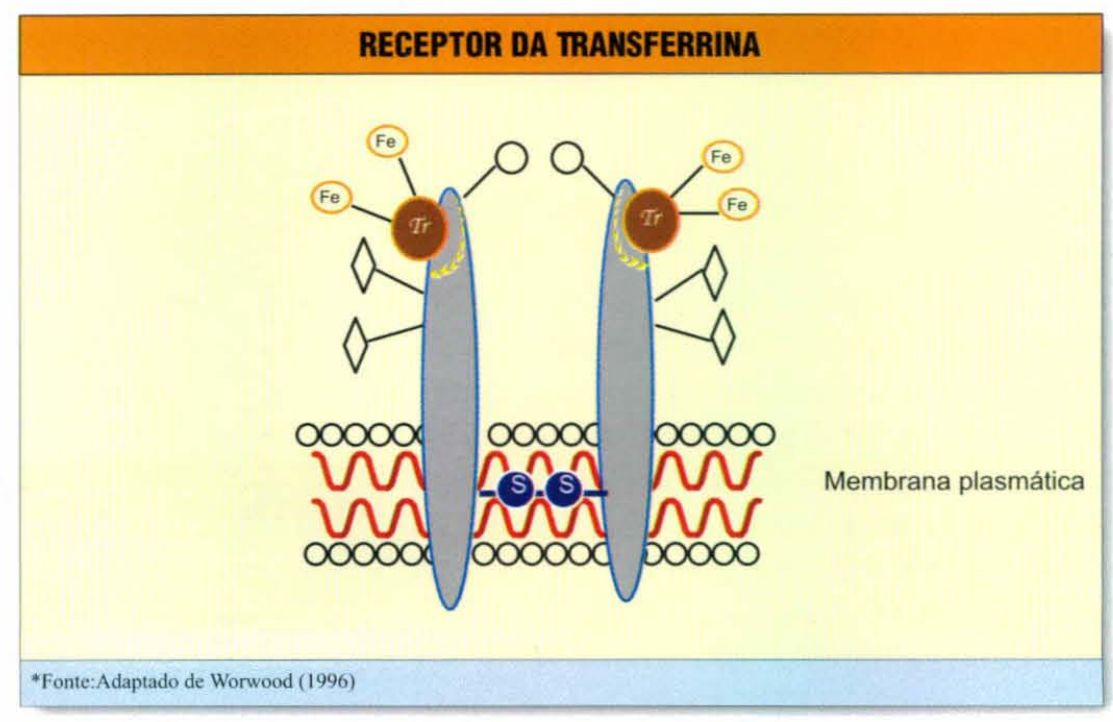

Se a transferrina estiver livre de fer-

Figura 4 - Representação da molécula do receptor da transferrina.

ro, não se orienta a nenhum alvo específico; entretanto, se estiver ligada ao ferro, deixa o plasma rapidamente para suprir prioritariamente o eritron (MELO, 1984). Quando a transferrina está totalmente saturada, encaminha-se para as células do parênquima hepático (NIMEH; BISHOP, 1980) e trato gastrintestinal (MELO, 1984), onde o ferro é armazenado sob a forma de ferritina ou hemossiderina.

Embora o conceito de um receptor específico da transferrina tenha sido estabelecido por Jandl e Katz (1963), houve pouco progresso na sua caracterização. Com a descoberta de anticorpos monoclonais específicos capazes de co-precipitar a transferrina marcada (pelo rádio) e bloquear a captação de ferro pela transferrina, tornou-se possível a identificação dessa estrutura (Figura 4) (TROWBRIDGE; CHACKELFORD, 1986).

A determinação dos níveis do receptor da transferrina tornou-se uma importante ferramenta diagnóstica, uma vez que a concentração do receptor circulante está relacionada com o nível de eritropoiese, aumentando também na deficiência de ferro (WORWOOD, 1996).

\section{Utilização do ferro para eritropoiese}

É sabido que a transferrina participa não apenas no transporte do ferro dos capilares da submucosa intestinal para os órgãos alvo (medula óssea, figado, etc.), como também participa diretamente da entrada do ferro para o interior da célula por meio da internalização do ferro carreado por esta proteína (NIMEH; BISHOP, 1980; SMITH, 1997).

A interação entre a transferrina e as células eritróides faz-se por meio de um grande número de receptores de membrana, presentes nos eritroblastos (vários milhões), nos reticulócitos (centenas de milhares) e ausentes nos eritrócitos maduros (MELO, 1984).

A quantidade de ferro liberado para o eritrócito imaturo depende da concentração do ferro sérico, da porcentagem de saturação da transferrina pelo ferro e do número de receptores de membrana (SMITH, 1997).

O processo de entrada do ferro na célula iniciase com a junção do receptor ao complexo Fe-tranferrina em sítios especializados da membrana denominados "Coated Pits" (CP). Esses sítios são revestidos na superfície interna por uma proteína fibrosa denominada "clathrin" (CL). Com a união do receptor ao complexo Fe-transferrina, o CP da membrana invagina-se formando uma vesícula, na qual a superfície interna será constituída pela membrana plasmática exterior e o receptor ligado ao complexo Fe-transferrina. $\mathrm{O}$ revestimento exterior da vesícula é constituído pela proteína CL. As vesículas dão origem a estruturas denominadas CDRL (compartimento de desacoplamento do receptorligante), onde, pela ação de uma enzima da membrana endosômica, ocorre a redução do $\mathrm{pH}$ interno. No pH baixo, a afinidade da transferrina pelo ferro diminui e o ferro é liberado. A transferrina livre do ferro (apotransferrina) permanece ligada ao receptor e é transportada de volta para a superfície celular. Ao atingir a superfície, na presença de $\mathrm{pH}$ neutro, a apotransferrina é liberada do receptor. Depois de liberada, pode ligar-se novamente ao ferro e o receptor fica disponível para ligar-se a outros complexos Fetransferrina(SMITH, 1997). 


\section{Absorção e excreção do ferro}

A quantidade de ferro disponível para absorção pelo intestino depende da quantidade de ferro na dieta e da sua biodisponibilidade (ANDERSON et al., 1990; SMITH, 1997).

A absorção do ferro é influenciada ainda por outros fatores. $\mathrm{O}$ ferro heme é absorvido rapidamente, independentemente da composição da dieta; por outro lado, o ferro não-heme é altamente indisponível e sua absorção é afetada por ingredientes da dieta (SMITH, 1997). Substâncias como os tanatos e fosfatos inibem a absorção do ferro, já o ácido ascórbico e a carne contribuem com a absorção do ferro não-heme (FINCH; COOK, 1984; ANDERSON et al., 1990; HAYS; SWENSON, 1996; WORWOOD, 1996).

O mecanismo exato de absorção do ferro não está totalmente esclarecido, entretanto, recentes trabalhos têm preenchido algumas lacunas a respeito deste mecanismo (SMITH, 1997).

No estômago, o alimento sofre digestão péptica e libera o ferro, seja na sua forma heme, seja na forma de ferro iônico, que rapidamente forma complexos de ferro solúveis ou insolúveis (WORWOOD, 1996). O ferro liberado do alimento liga-se a quelatos de alto peso molecular. Esses quelatos e o ácido clorídrico provavelmente estabilizam o ferro em uma forma solúvel $\left(\mathrm{Fe}^{2+}\right)$, evitando a formação de complexos férricos insolúveis (NIMEH; BISHOP, 1980).

Após a fase de digestão, a absorção processase em duas etapas: captação e transferência. A maior captação do ferro ocorre no duodeno e jejuno superior (MELO, 1984). WORWOOD, (1996) propos que as integrinas, proteínas transmembranas, seriam as mediadoras dessa permuta. Além disso, existe comprovação recente sobre a existência de $\mathrm{Fe}^{3+}$ redutase na membrana da borda em escova das células intestinais.

O transporte do ferro através da célula é possivelmente realizado por uma proteína intracelular, a mobiliferrina. Essa proteína solúvel, com massa molecular de $56 \mathrm{KDa}$, liga-se não só ao ferro, mas também ao zinco, cobalto e chumbo, explicando, talvez, a concorrência pela absorção entre o ferro e esses metais (WORWOOD, 1996).

A etapa final da absorção ocorre nos capilares da submucosa intestinal, onde o ferro é captado pela transferrina após sofrer oxidação pela ação de uma pro- teína, a ceruloplasmina, uma ferroxidase plasmática que converte o $\mathrm{Fe}^{2+}$ em $\mathrm{Fe}^{3+}$ (MILLER; RAMSEY; MADSEN, 1993; HAYS; SWENSON, 1996). Essa proteína responde pela interação entre o cobre, que faz parte da sua molécula, e o metabolismo do ferro. A oxidação do íon ferroso para a forma férrica é aumentada em 10 a 100 vezes pela ação da ceruloplasmina, na dependência das demandas de ferro nos órgãos eritropoiéticos. A ceruloplasmina atua ainda como um
ESTÔMAGO

(Integrinas, $\mathrm{Fe}^{-3}$ redutase)

vood (1996)

\section{MECANISMO DE ABSORÇĀO}

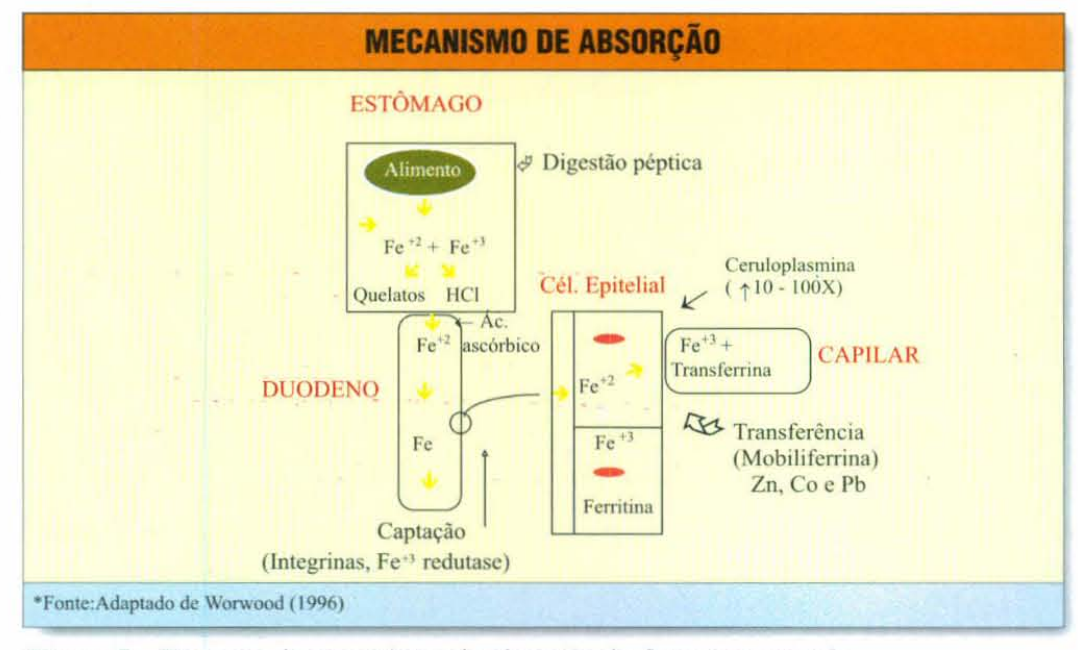

.

(1)

Figura 5 - Esquema do mecanismo de absorção do ferro nos animais.

mediador da liberação do ferro a partir da ferritina e hemossiderina (HAYS; SWENSON, 1996). Um esquema resumido do mecanismo de absorção é apresentado na Figura 5.

Diariamente são perdidas pequenas quantidades de ferro absorvido. A maior parte dessa perda ocorre pelas fezes, pela descamação das células mucosas e pelo ferro biliar não absorvido. O restante é perdido pela descamação cutânea e por excreção urinária, que representam normalmente uma perda muito pequena. (ANDERSON et al., 1990). Outras importantes causas de perda de ferro são as infecções parasitárias, a doação de sangue e as perdas mínimas de sangue no intestino decorrentes da ingestão de aspirina (WORWOOD, 1996).

\section{Regulação da absorção do ferro}

Nos indivíduos com deficiência de ferro a absorção deste elemento pelo intestino está aumentada, ao passo que naqueles com sobrecarga de ferro a sua absorção torna-se diminuída (Figura 6) (NIMEH; BISHOP, 1980).

Miller, Ramsey, Madsen (1993) e Worwood (1996) identificaram duas influências controladoras da absorção do ferro: primeiramente o nível das reservas 
de ferro e em menor grau as modificações na taxa de eritropoiese, porém o mecanismo exato de regulação da absorção do ferro em resposta às modificações do seu metabolismo ainda não é conhecido.

Acredita-se, atualmente, que a transferrina incorpora, de alguma maneira, um sinal do estado de ferro do organismo nas células mucosas recém-formadas (renovadas a cada dois a três dias), possivelmente pela quantidade de ferro que ela, a transferrina, conduz para estas células. As células mucosas regulam não só a captação do ferro que se encontra na luz do intestino como também sua liberação para o sangue (ANDERSON et al., 1990).

A disponibilidade do ferro a partir do plasma, programa a célula durante a diferenciação nas criptas de Lieberkühn, para um nível determinado de síntese, tanto do receptor da transferrina, quanto da apoferritina. Numa situação de deficiência, haverá uma baixa concentração de ferro no plasma e as células em desenvolvimento terão um número aumentado de receptores da transferrina e baixos níveis de síntese da apoferritina. À medida que a disponibilidade de ferro aumenta, diminuirá a síntese dos receptores e aumentará a apoferritina (Figura 7) (WORWOOD, 1996).

Miller, Ramsey, Madsen (1993) e Worwood (1996) identificaram duas influências controladoras da absorção do ferro: primeiramente o nível das reservas de ferro e em menor grau as modificações na taxa de eritropoiese, porém o mecanismo exato de regulação da absorção do ferro em resposta às modificações do seu metabolismo ainda não é conhecido.

Acredita-se, atualmente, que a transferrina incorpora, de alguma maneira, um sinal do estado de ferro do organismo nas células mucosas recém-formadas (renovadas a cada dois a três dias), possivelmente pela quantidade de ferro que ela, a transferrina, conduz para estas células. As células mucosas regulam não só a captação do ferro que se encontra na luz do intestino como também sua liberação para o sangue (ANDERSON et al., 1990).

A disponibilidade do ferro a partir do plasma, programa a célula durante a diferenciação nas criptas de Lieberkühn, para um nível determinado de síntese, tanto do receptor da transferrina, quanto da apoferritina.

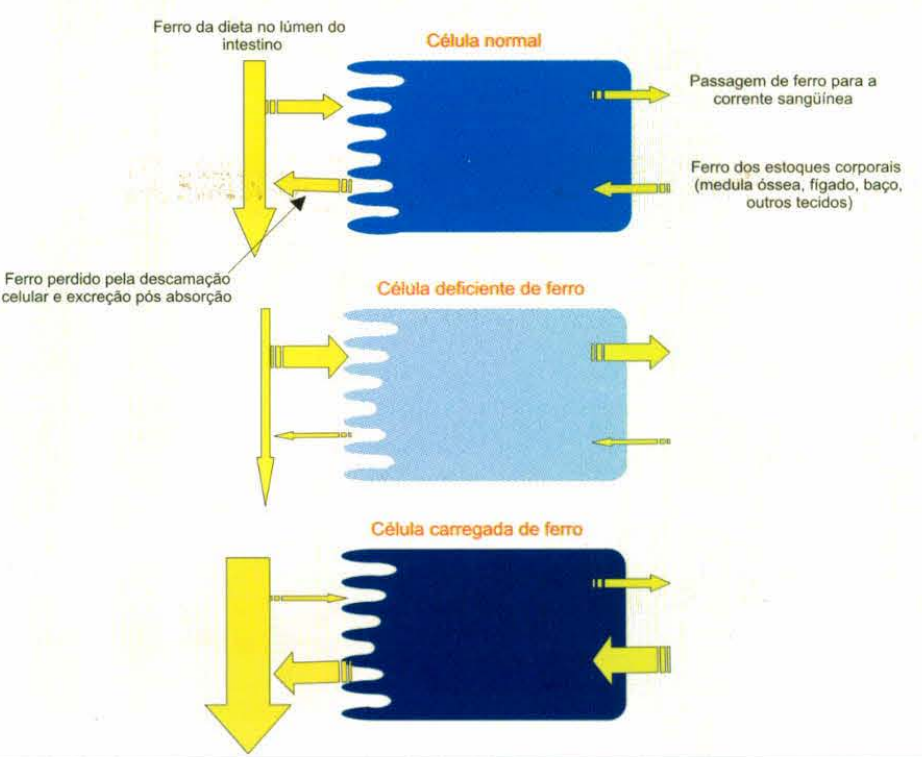

Fonte:adaptado de Dale \& Federman (1996)

Figura 6 - Regulação da absorção de ferro pelas células intestinais

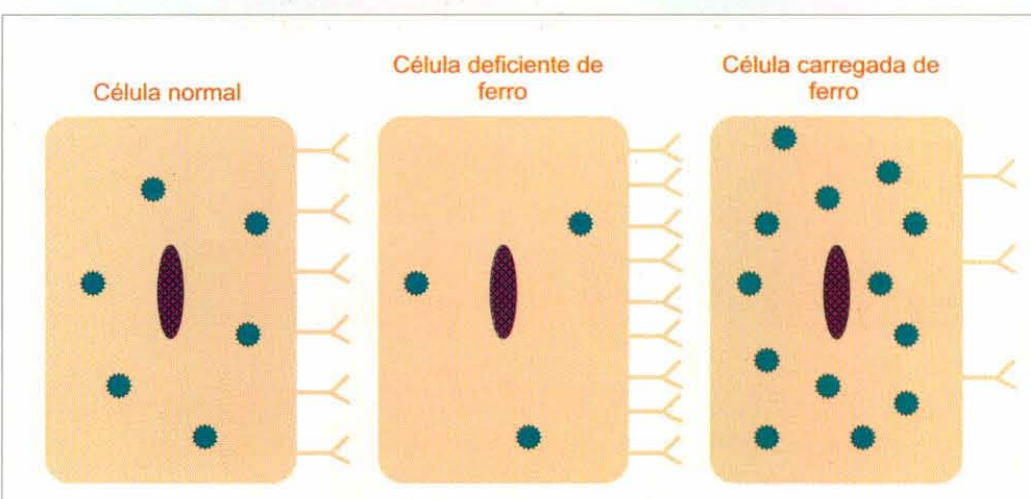

- Receptor da transferrina

- Apoferritina

Figura 7 - Representação da sintese de receptores da transferrina e de apoferritina em diferentes estoques de ferro orgânico.

Numa situação de deficiência, haverá uma baixa concentração de ferro no plasma e as células em desenvolvimento terão um número aumentado de receptores da transferrina e baixos níveis de síntese da apoferritina. À medida que a disponibilidade de ferro aumenta, diminuirá a síntese dos receptores e aumentará a apoferritina (Figura 7) (WORWOOD, 1996).

\section{Testes para avaliação das reservas do ferro}

As alterações do metabolismo do ferro podem ser avaliadas por meio de várias provas laboratoriais, 
sendo estas de fundamental importância para o diagnóstico diferencial dos distúrbios que envolvem esse metabolismo.

\begin{tabular}{|l|c|c|c|c|}
\hline ESPÉCIES FERRO & \multicolumn{3}{c|}{ HEME } & NÃO-HEME \\
\hline Cão (10kg) & 9 & $\%$ & G & $\%$ \\
\hline Cavalo (400 kg) & 11,5 & 67 & 5,60 & 33 \\
\hline Vaca (386 kg) & 9,20 & 55 & 7,70 & 45 \\
\hline Homem (70kg) & 3,19 & 76 & 1,01 & 24 \\
\hline Fonte: Kaneko et al., 1997 & & & \\
\hline
\end{tabular}

Quadro 1 - Distribuição do ferro em componentes heme e não-heme.

\begin{tabular}{|c|c|c|c|}
\hline ESPÉCIES & $\begin{array}{c}\text { FERRO SÉRICO } \\
\text { (mg/dL) }\end{array}$ & $\begin{array}{c}\text { CTLF } \\
\text { (mg/dL) }\end{array}$ & $\begin{array}{c}\text { FERRITINA } \\
\text { (ng/mL) }\end{array}$ \\
\hline Cão & $33-147$ & $282-386$ & $80-800$ \\
\hline Gato & $33-135$ & $169-325$ & $32-123$ \\
\hline Bovino & $39-155$ & $186-270$ & $33-55$ \\
\hline Eqüino & $50-198$ & $231-455$ & $43-261$ \\
\hline Ovino & $179-207$ & $298-370$ & - \\
\hline Suíno & $55-187$ & $241-393$ & $20-125$ \\
\hline
\end{tabular}

Fonte: Kaneko et al., 1997

Quadro 2 - Determinação do ferro no soro de animais domésticos.

Muitos testes são empregados para esse fim, entretanto, apenas alguns deles, de fácil execução no laboratório, são utilizados rotineiramente, tais como: os testes hematológicos, a determinação sérica do ferro, da capacidade total de ligação do ferro (CTLF) e do índice de saturação da transferrina (IST) (Quadros 1 e 2) e, ainda, a avaliação do ferro medular.

\section{Testes hematológicos}

Com certas restrições, os exames hematológicos podem ser usados para avaliar o status do ferro nos animais domésticos. O sangue pode ser obtido facilmente e se constitui no maior compartimento de ferro do organismo (hemoglobina). Entretanto, o ferro é preferencialmente desviado de outros compartimentos para a síntese de hemoglobina, sendo assim, a hemoglobina pode ser a última a demonstrar o efeito da inadequação do ferro (SMITH, 1997).
A contagem total de hemácias, a determinação do hematócrito, da concentração da hemoglobina e dos índices hematimétricos (VCM, HCM, CHCM) são os testes hematológicos indicados para a avaliação do metabolismo do ferro.

Em razão de os índices eritrocitários estarem geralmente normais durante o estágio inicial da deficiência, a maioria dos casos de deficiência de ferro permanecem sem um diagnóstico até estágios mais avançados. A deficiência crônica de ferro é caracterizada pela presença de anemia microcítica hipocrômica (HARVEY, 2000).

Ferro sérico, Capacidade total de ligação do ferro e Índice de saturação da transferrina

O ferro pode ser determinado pela espectrofotometria de absorção atômica ou por métodos colorimétricos. A mensuração direta do ferro sérico pela absorção atômica pode dar resultados pouco confiáveis em razão da sensibilidade limitada deste método, uma vez que o ferro da hemoglobina pode não ser distinguido do ferro da transferrina. Na determinação colorimétrica, o ferro é separado da transferrina pela diminuição do $\mathrm{pH}$ e, depois, reduzido à sua forma ferrosa. Dessa maneira, torna-se possível, pelo método colorimétrico, realizar a determinação em amostras ligeiramente hemolisadas ou na presença de outros componentes, como a bilirrubina, os lipídeos ou o colesterol, sem que o resultado seja seriamente afetado (SMITH, 1997).

A transferrina total pode ser medida por métodos imunológicos, porém não são comumente usados. Usualmente, a transferrina é medida indiretamente pela concentração de ferro depois de ter sido saturada com este elemento. Quando a transferrina é saturada com uma concentração conhecida de ferro, a quantidade de ferro é chamada de capacidade total de ligação do ferro (CTLF). Pelo fato de a transferrina poder ligar uma quantidade maior de ferro do que a que está normalmente presente no soro, a CTLF é maior do que o ferro sérico, e a diferença entre eles é denominada de capacidade latente de ligação do ferro. Dessa forma, o ferro sérico pode ser expresso como uma porcentagem da CTLF, sendo reportado como índice de saturação da transferrina (IST) (HENRY; CANNON; WINKELMAN, 1974; HAYS; SWENSON, 1996).

\section{Ferritina sérica}

Embora as funções da ferritina estejam relacionadas como o componente de estoque de ferro e seja 


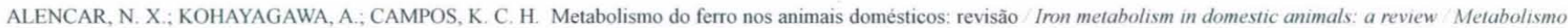

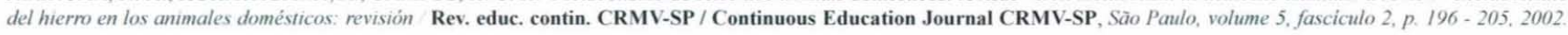

primariamente intracelular, ela pode ser detectada no soro. Em humanos, concentrações de ferritina sérica estão correlacionadas com o estoque corporal total de ferro. A concentração da ferritina está baixa na deficiência de ferro e elevada na sobrecarga deste elemento (ANDREWS; SMITH, 2000).

Addison et al. (1972) foram os primeiros a demonstrar, por meio de ensaio radioimunométrico, que havia ferritina em quantidades mensuráveis no plasma normal e que a concentração deste componente estava relacionada com as reservas orgânicas de ferro.

Uma limitação deste teste é, sem dúvida, a necessidade de se isolar a ferritina e produzir anticorpos antiferritina específicos para cada espécie, o que o torna caro e de difícil execução no laboratório.

A adequada avaliação deste teste passa obrigatoriamente pelo entendimento de que a ferritina é também uma proteína de fase aguda da inflamação e, por isso, resultados normais desse composto devem ser analisados, com critério, nos processos inflamatórios severos. Nestes casos recomenda-se a determinação de outras proteínas de fase aguda, tais como a haptoglobina, a proteína $\mathrm{C}$ reativa e o fibrinogênio (SMITH, 1997).

A ferritina eleva-se nos processos inflamatórios do figado provavelmente pelo mesmo mecanismo das transaminases. Há descrições de elevação também nas leucemias mieloblástica e linfoblástica agudas, no linfoma, na doença de Hodgkin, no carcinoma de mama e no mieloma múltiplo (KRAUSE; STOLC, 1979; NIMEH; BISHOP, 1980).

A deficiência de ferro é a principal causa relacionada com baixos níveis de ferritina sérica.

\section{Ferro medular}

Exames citológicos da medula óssea são úteis para avaliação de distúrbios do metabolismo do ferro. A reação do Azul-da-Prússia, em que o ferro iônico reage com uma solução ácida de ferrocianeto produzindo uma cor azul, é comumente utilizada para esse fim (SMITH, 1997).
Pode-se avaliar as reservas de ferro corandose os tecidos com o Azul-da-Prússia. Isto se aplica especialmente em preparados da medula óssea e nas biopsias hepáticas. Pode-se dizer que a presença de ferro corável nas células reticuloendoteliais da medula óssea elimina a deficiência de ferro como causa da anemia (NIMEH; BISHOP, 1980).

O termo siderócito foi introduzido, em 1941, por Gruneberg, para indicar a presença de eritrócitos que contenham grânulos de ferro corados pela reação do Azul-da-Prússia. Aos eritrócitos nucleados que contêm grânulos de ferro corados, denominamos sideroblastos (HARVEY, 1997).

Exceto nos gatos, a medula óssea de animais domésticos adultos exibe ferro corável (hemossiderina) dentro de macrófagos. Na deficiência de ferro, macrófagos e eritrócitos em desenvolvimento não contêm grânulos de ferro coráveis. Por outro lado, quando a síntese do heme está prejudicada, a mitocôndria acumula excesso de agregados amorfos de ferro e um grande anel de grânulos sideróticos azuis rodeiam o núcleo do eritroblasto (SMITH, 1997).

Segundo Krause e Stolc (1979), a grande vantagem da avaliação do ferro medular em relação às determinações séricas de ferro, CTLF e IST, é que estes podem não diferenciar a depleção dos estoques de ferro das condições associadas aos defeitos da liberação do ferro pelo sistema mononuclear fagocitário, como ocorre na anemia da doença inflamatória (ADI).

A anemia da doença inflamatória (ADI) é uma anemia não-regenerativa, de leve a moderada, com característica normocítica normocrômica associada com processo inflamatório, infecções crônicas, condições traumáticas, tais como lesão tecidual ou fratura, e doença neoplásica disseminada ou necrozante. Esse é o tipo de anemia mais comum em pequenos animais e é provavelmente a mais comum em Medicina Veterinária. A hipoferremia resultante da ADI pode ser considerada um mecanismo imune antibacteriano não específico. O ferro é vital para o crescimento dos microor-ganismos, e a infecção é suprimida pela retenção do ferro no interior das células. Esse seqüestro do ferro é a base da patogênese daADI (WARNER; HARRUS, 2000). 


\section{SUMMARY}

Disorders of iron metabolism are both the main cause of iron deficiency anemia in small animals and the most commonly encountered deficiency in veterinary medicine. Iron metabolism assumes a fundamental role in the study of anemia. Although there are still many gaps, recent advances have resulted in a better understanding of the effects of iron imbalance. The objective of this paper was to present a review on iron metabolism in domestic animals, emphasizing the tests to evaluate this metabolism.

Key words: Iron metabolism. Anemia. Hematology. Bone marrow.

\section{RESUMEN}

El estudio del metabolismo del hierro ha sido de fundamental importancia para poder comprender los procesos mórbidos que incluye este metabolismo, como las anemias con carencia de hierro y la anemia de enfermedad inflamatoria, que es la principal causa de la anemia en pequeños animales y probablemente la anemia más comúnmente encontrada en la medicina veterinaria. A pesar de que aún persistan muchas brechas en la comprensión de este metabolismo, recientes avances han resultado en un entendimiento más cabal sobre los efectos provocados por los desequilibrios de este elemento. El propósito de este trabajo ha sido el de presentar una revisión sobre el metabolismo del hierro en las especies domésticas enfatizando los análisis laboratoriales utilizados para evaluar dicho metabolismo.

Palabras clave: Metabolismo del hierro. Anemia. Hematología. Médula ósea.

\section{REFERÊNCIAS}

ADDISON, G. L. et al. An immunoradiometric assay for ferritin in the serum of normal subjects and patients with iron deficiency and overload. Journal of Clinical Pathology, v. 25, p. 326-329, 1972.

ANDERSON, L. et al. Metabolismo mineral In: Nutrição. Rio de Janeiro: Guanabara Koogan, 1990. p. 63-92.

ANDREWS, G. A.; SMITH, J. E. Iron metabolism. In: FELDMAN, B. F.; ZINKL, J. G.; JAIN, N. C. Schalm's veterinary hematology. Philadelphia: Lippincott Williams \& Wilkins, 2000. p. 129-34.

DALE, D. C.; FEDERMAN, D. D. Scientific American: medicine. New York: Scientific American, 1996. sec. 4, (n. 11/96).
FINCH, C. A.; COOK, J. D. Iron deficiency. The American Journal of Clinical Nutrition, v. 39, n. 3, p. 471-477, 1984.

GRUNEBERG, H. Siderocytes: a new kind of erythrocyte. Nature, v. 148, p. 114, 1941.

HARVEY, J. W. The erythrocyte: physiology, metabolism and biochemical disorders. In: KANEKO, J. J.; HARVEY, J. W.; BRUSS, M. L. Clinical biochemistry of domestic animals. New York: Academic Press, 1997. p. 157-204.

HARVEY, J. W. Microcytic anemias. In: FELDMAN, B. F.; ZINKL, J. G.; JAIN, N. C. Schalm's veterinary hematology. Philadelphia: Lippincott Williams \& Wilkins, 2000. p. 200-204. 
HAYS, V. W.; SWENSON, M. J. Minerais. In: SWENSON, M. J.; REECE, W. O. Dukes fisiologia dos animais domésticos. Rio de Janeiro: Guanabara Koogan, 1996. p. 471-487.

HENRY, R. J.; CANNON, D. C.; WINKELMAN, J. W. In: Clinical chemistry: principles and techniques. New York: Harper \& Row, 1974. p. 687-695.

JANDL, J. H.; KATZ, J. H. The plasma-to-cell cycle of transferrin. Journal of Clinical Investigation, v. 42, p. 314-326, 1963.

KANEKO, J. J.; HARVEY, J. W.; BRUSS, M. L. Clinical biochemistry of domestic animals. New York: Academic Press, 1997. $932 \mathrm{p}$.

KRAUSE, J. R.; STOLC, V. Serum ferritin and bone marrow iron stores. I: Correlation with absence of iron in biopsy specimens. American Journal of Clinical Pathology, v. 72, p. 817-820, 1979.

MELO, L. N. Aspectos fisiopatológicos do metabolismo de ferro em pacientes portadores de síndrome anêmico. 1984. $146 \mathrm{f}$. Dissertação (Mestrado) - Faculdade de Medicina de Botucatu, Universidade Estadual Paulista, Botucatu, 1984

MILLER, J. K.; RAMSEY, N.; MADSEN, F. C. Elementos vestigiales. In: El rumiante. Fisiología digestiva y nutrición. Zaragoza: Acribia, 1993. p. 391-457.
NIMEH, N.; BISHOP, R. C. Distúrbios do metabolismo do ferro. Clínicas Médicas da América do Norte, p. 633-648, jul. 1980.

SCHMIDH-NIELSEN, K. Metabolismo energético. In: Fisiologia animal - Adaptação e Meio Ambiente. São Paulo: Santos Livraria, 1999. p. 169-214.

SMITH, J. E. Iron metabolism and its diseases. In: KANEKO, J. J.; HARVEY, J. W.; BRUSS, M. L. Clinical biochemistry of domestic animals. New York: Academic Press, 1997. p. 223-240.

THORBECKE, G. J. et al. Sites of formation of the serum proteins transferrin and hemopexin. Journal of Clinical Investigation, v. 52, p. 725-731, 1973.

TROWBRIDGE, I. S.; CHACKELFORD, D. A. Structure and function of transferrin receptors and their relationship on to cell growth. Biochemical Society Symposia, v. 51, p. 117-129,1986.

WARNER, T.; HARRUS, S. Anemia of inflammatory disease. In: FELDMAN, B. F.; ZINKL, J. G.; JAIN, N. C. Schalm's veterinary hematology. Philadelphia: Lippincott Williams \& Wilkins, 2000. p. 205-209.

WORWOOD, M. Ferritin. Blood Reviews, v. 4, p. 259-269,1990.

WORWOOD, M. Regulação do metabolismo do ferro. Anais Nestlé, v. 52, p. 1-10, 1996. 